\title{
Renierosides, Cerebrosides from a Marine Sponge Haliclona (Reniera) sp.
}

Tayyab A. Mansoor, ${ }^{\dagger, \nabla}$ Pramod B. Shinde,${ }^{\dagger}$ Xuan Luo, ${ }^{\dagger}$ Jongki Hong, ${ }^{\dagger}$ Chong-O. Lee,${ }^{\S}$ Chung Ja Sim, ${ }^{\perp}$ Byeng Wha Son, $"$ and Jee H. Jung ${ }^{*} \dagger$

College of Pharmacy, Pusan National University, Busan 609-735, Korea, College of Pharmacy, Kyung Hee University, Seoul 130-701, Korea, Korea Research Institute of Chemical Technology, Daejon 305-343, Korea, Hannam University, Daejon 306-791, Korea, Basic Science Research Institute, Pukyong National University, Busan 608-737, Korea and Faculdade de Farmácia, Universidade de Lisboa, Av. D. Forças Armadas, Lisboa 1600-083, Portugal.

\section{Supporting Information}

\section{Index:}

Figure S1: ${ }^{1} \mathrm{H}$ NMR spectrum of compound 1 (500 MHz, $\left.\mathrm{CD}_{3} \mathrm{OD}\right)$.

Figure S2: HSQC spectrum of compound 1 (500 MHz, $\mathrm{CD}_{3} \mathrm{OD}$ ).

Figure S3: Low resolution FAB mass spectrum of compound 1.

Figure S4: FAB-CID tandem mass spectrum of FAME of compound 1.

Figure S5: ${ }^{1} \mathrm{H}$ NMR spectrum of compound 6 (500 MHz, $\mathrm{CD}_{3} \mathrm{OD}$ ).

Figure S6: HSQC spectrum of compound 6 (500 MHz, $\mathrm{CD}_{3} \mathrm{OD}$ ).

Figure S7: Low resolution FAB mass spectrum of compound 6.

Figure S8: FAB-CID tandem mass spectrum of FAME of compound 6.

Figure S9: FAB-CID tandem mass spectrum of FAME of compound 2.

Figure S10: FAB-CID tandem mass spectrum of FAME of compound 8.

Figure S11: Color photograph of the sponge Haliclona (Reniera) sp.

\footnotetext{
* To whom correspondence should be addressed. Tel: 82-51-510-2803. Fax: 82-51-513-6754. E-mail: jhjung@pusan.ac.kr.

${ }^{\dagger}$ Pusan National University.

${ }^{\ddagger}$ Kyung Hee University.

${ }^{\S}$ Korea Research Institute of Chemical Technology.

${ }^{\perp}$ Hannam University.

\| Pukyong National University.

${ }^{\nabla}$ Unversidade de Lisboa.
} 


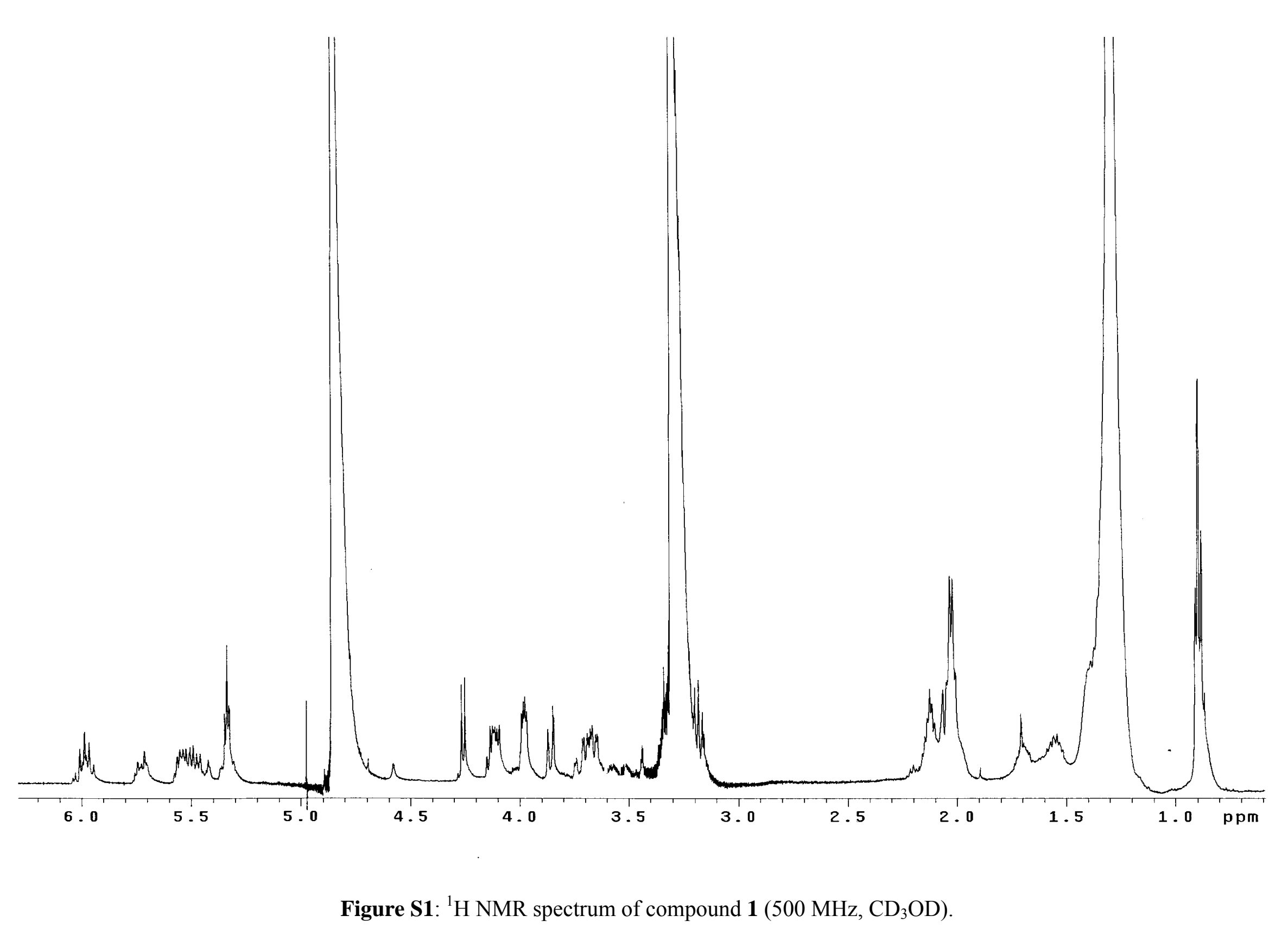




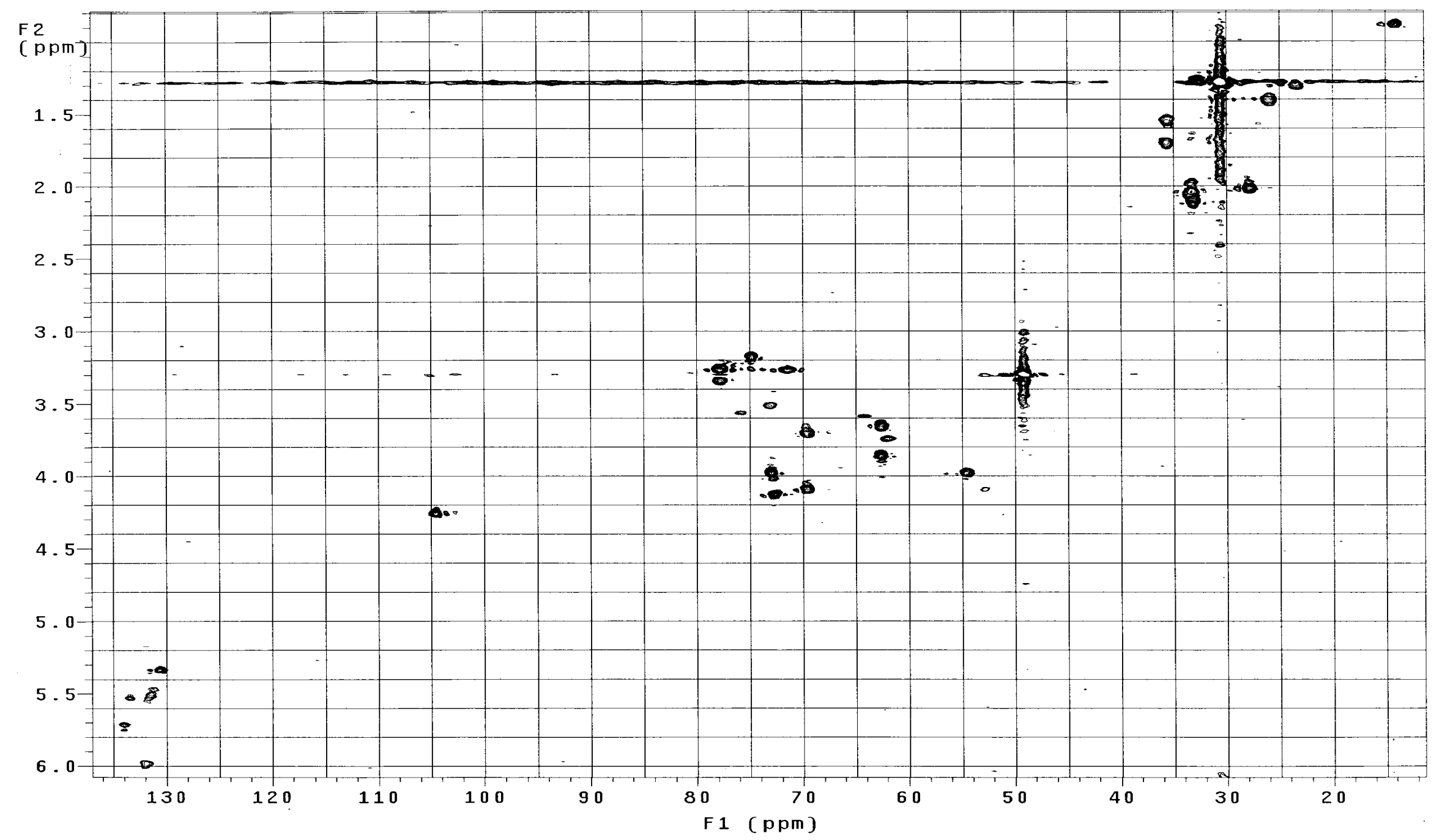

Figure S2: HSQC spectrum of compound $1\left(500 \mathrm{MHz}, \mathrm{CD}_{3} \mathrm{OD}\right)$. 


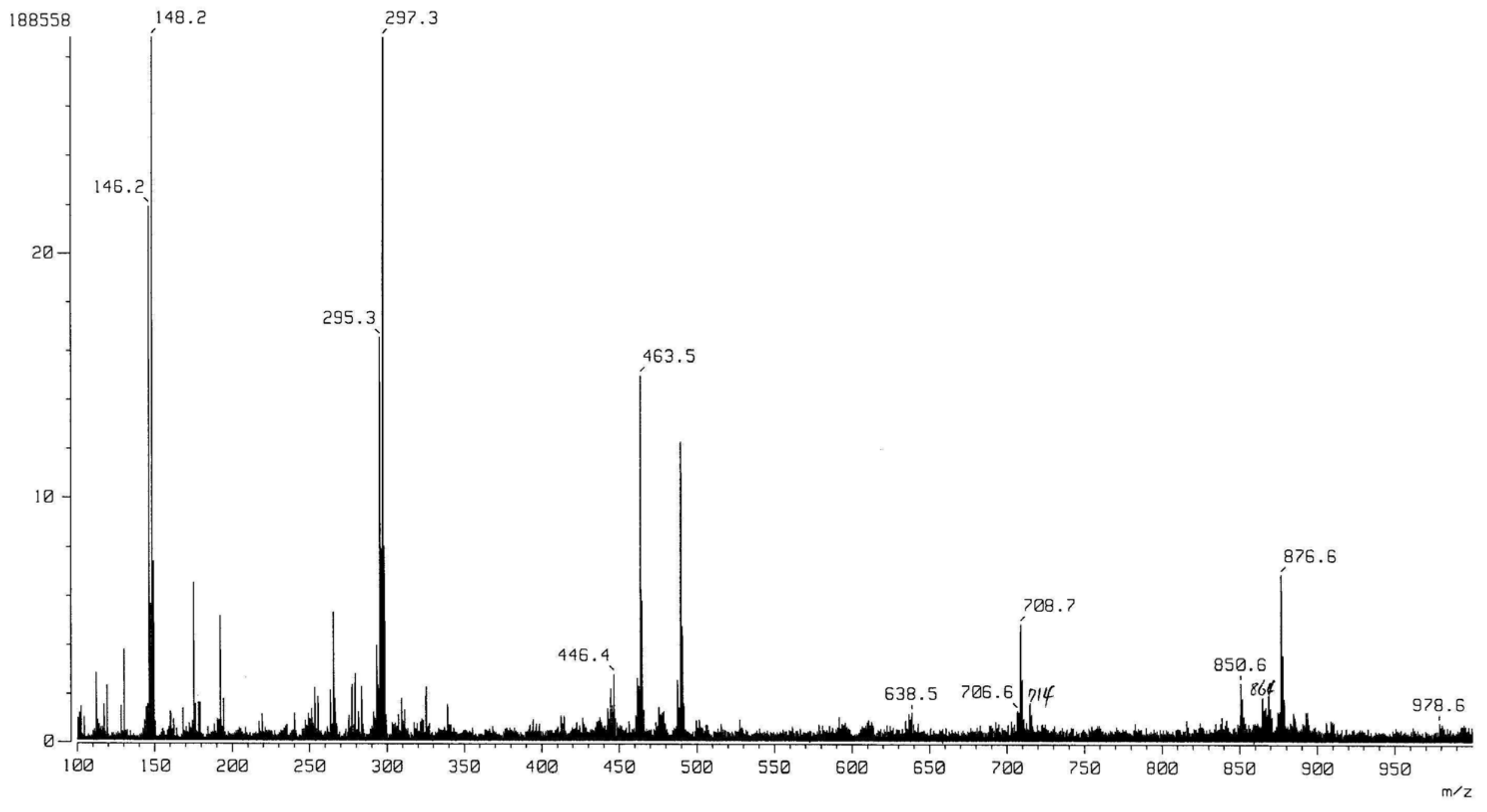

Figure S3: Low resolution FAB mass spectrum of compound 1. 


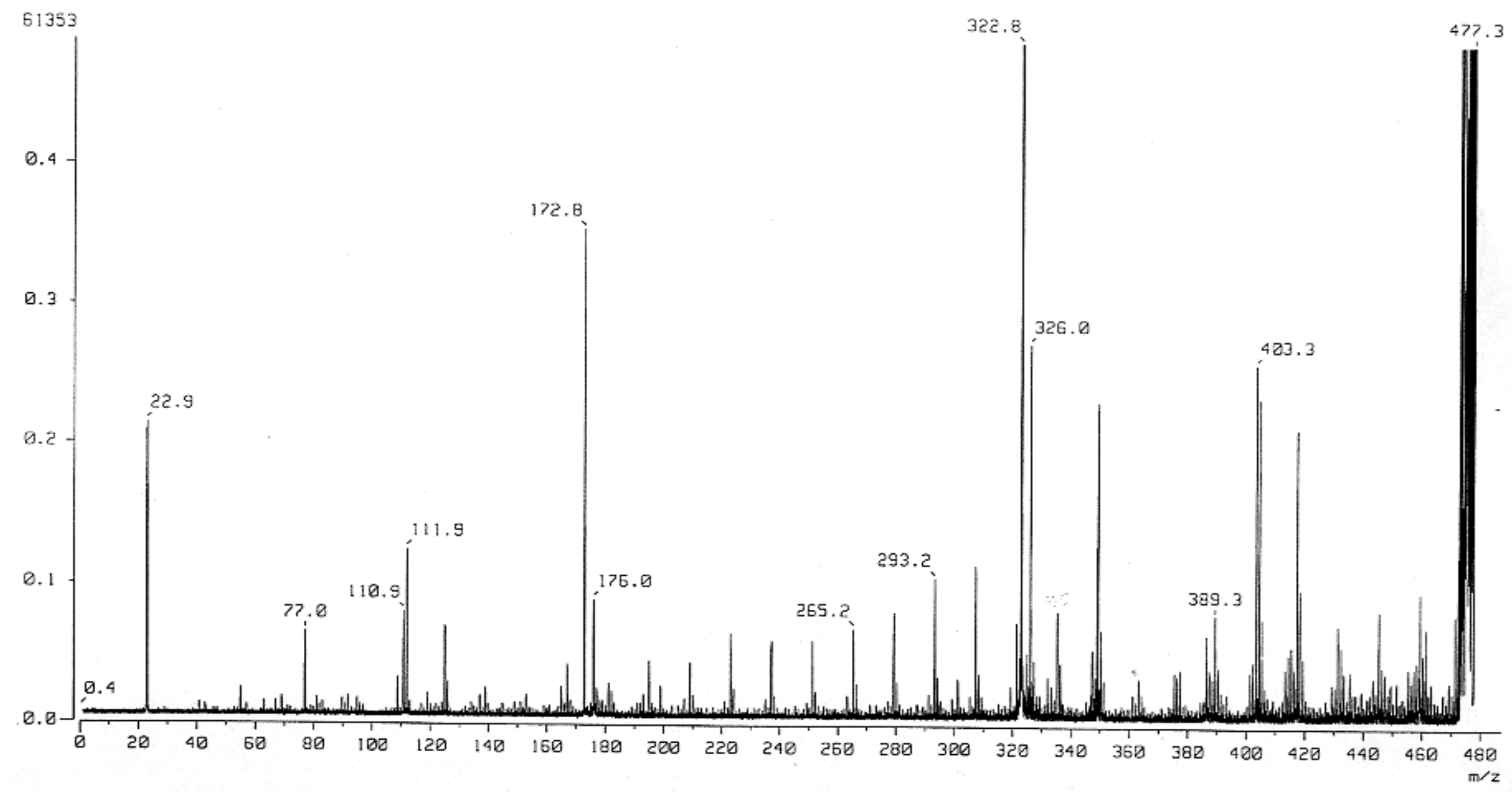

Figure S4: FAB-CID tandem mass spectrum of FAME of compound 1. 


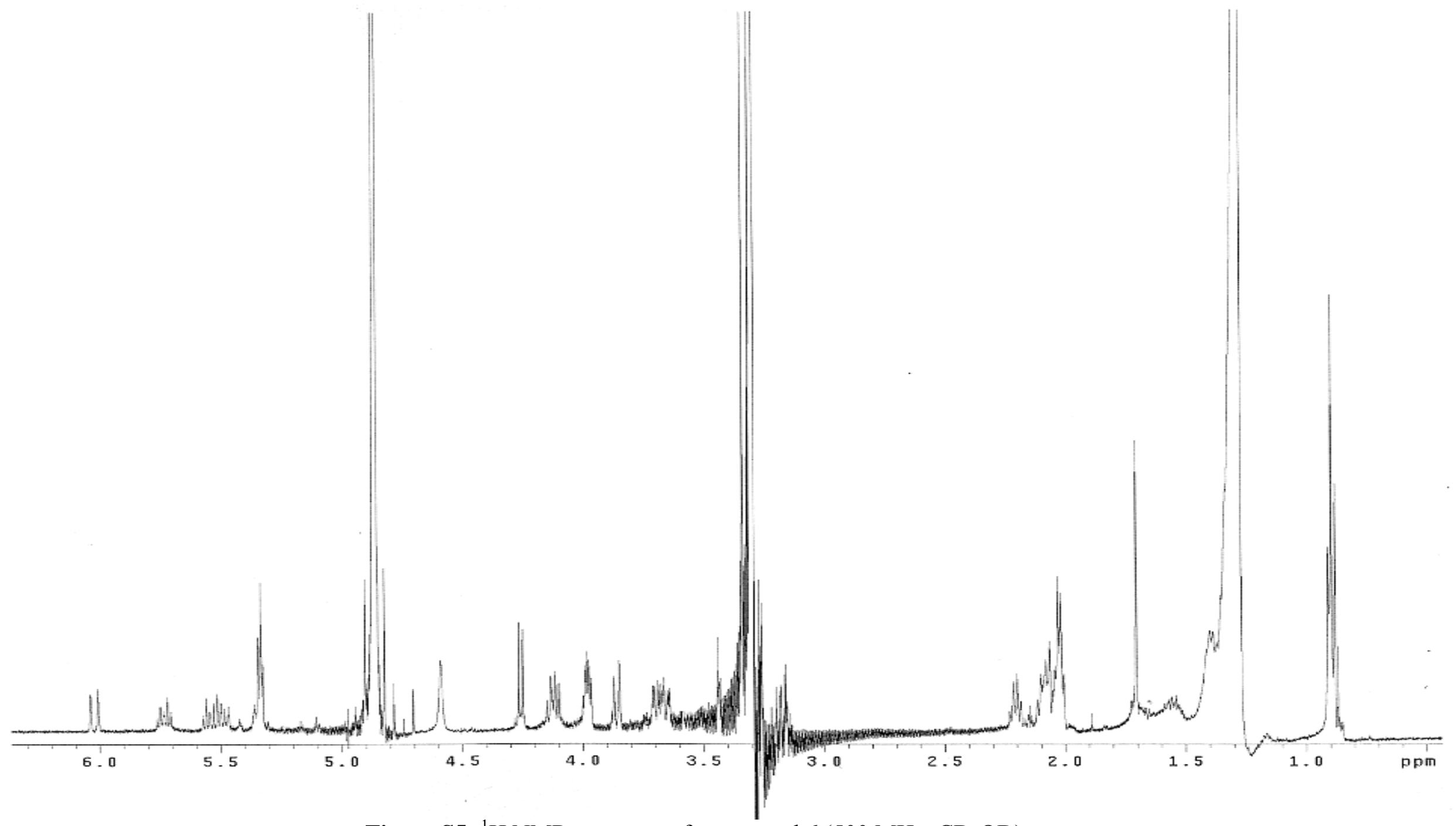

Figure S5: ${ }^{1} \mathrm{H}$ NMR spectrum of compound 6 (500 MHz, $\left.\mathrm{CD}_{3} \mathrm{OD}\right)$. 


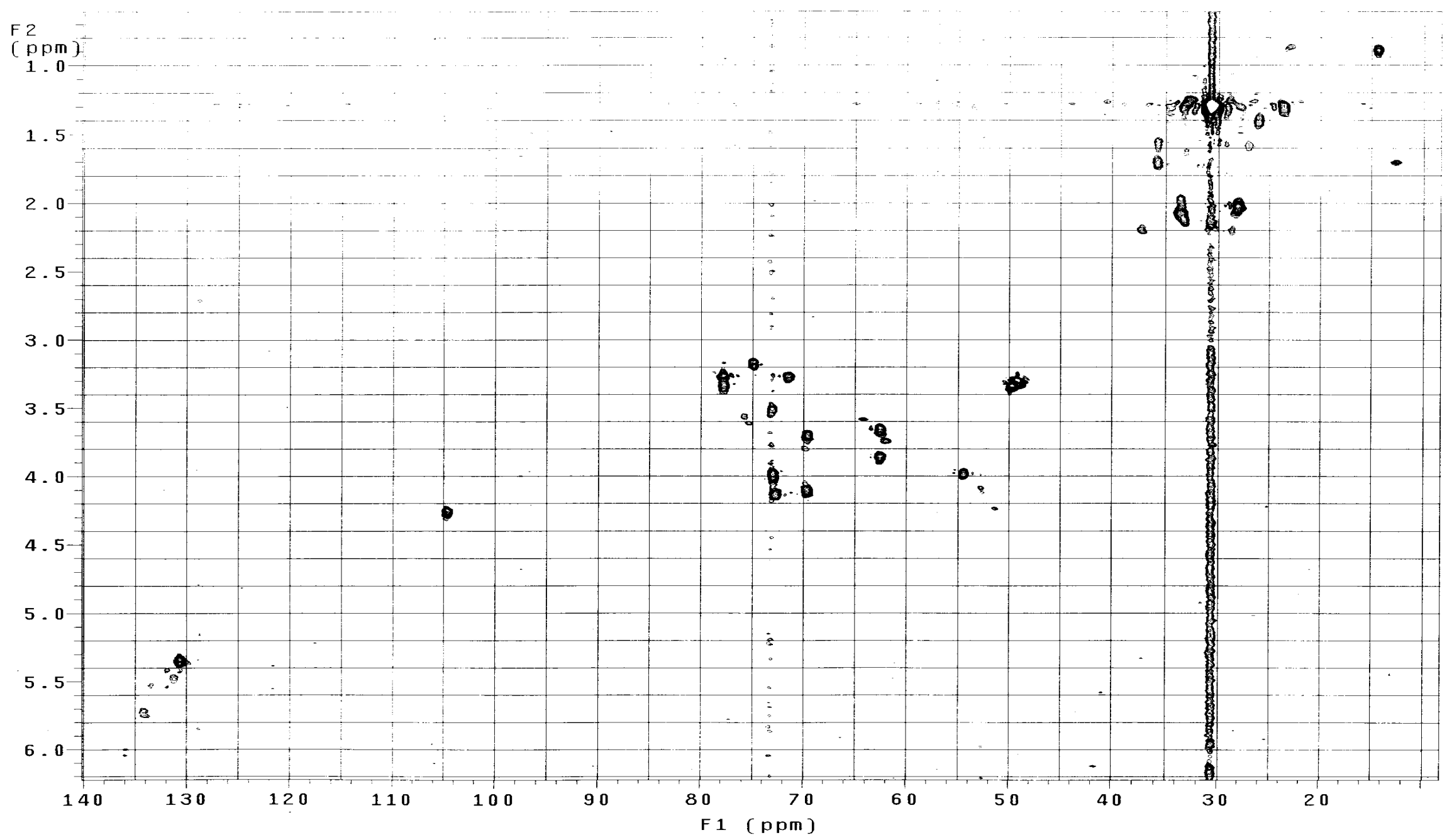

Figure S6: HSQC spectrum of compound 6 (500 MHz, $\left.\mathrm{CD}_{3} \mathrm{OD}\right)$. 


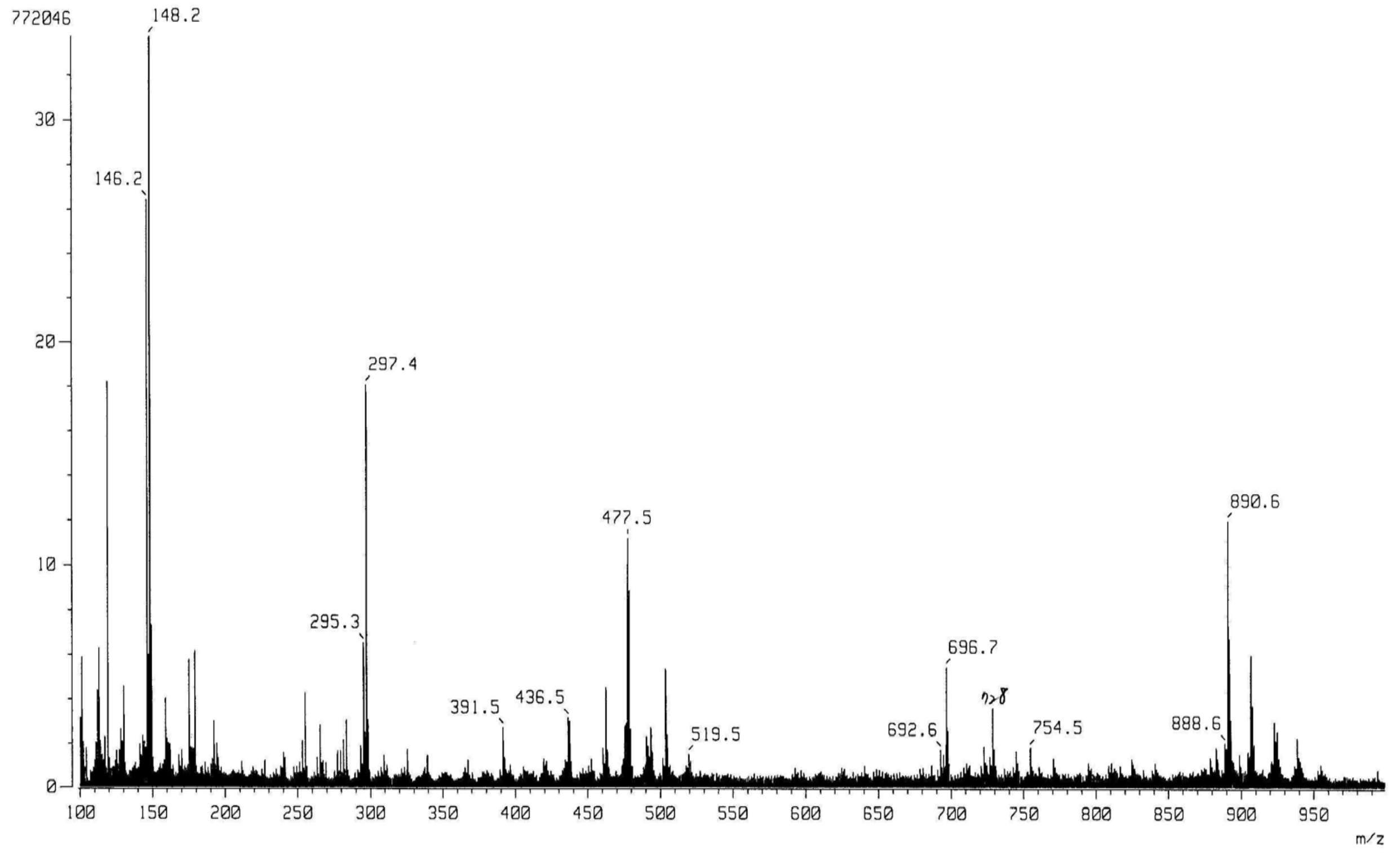

Figure S7: Low resolution FAB mass spectrum of compound 6. 


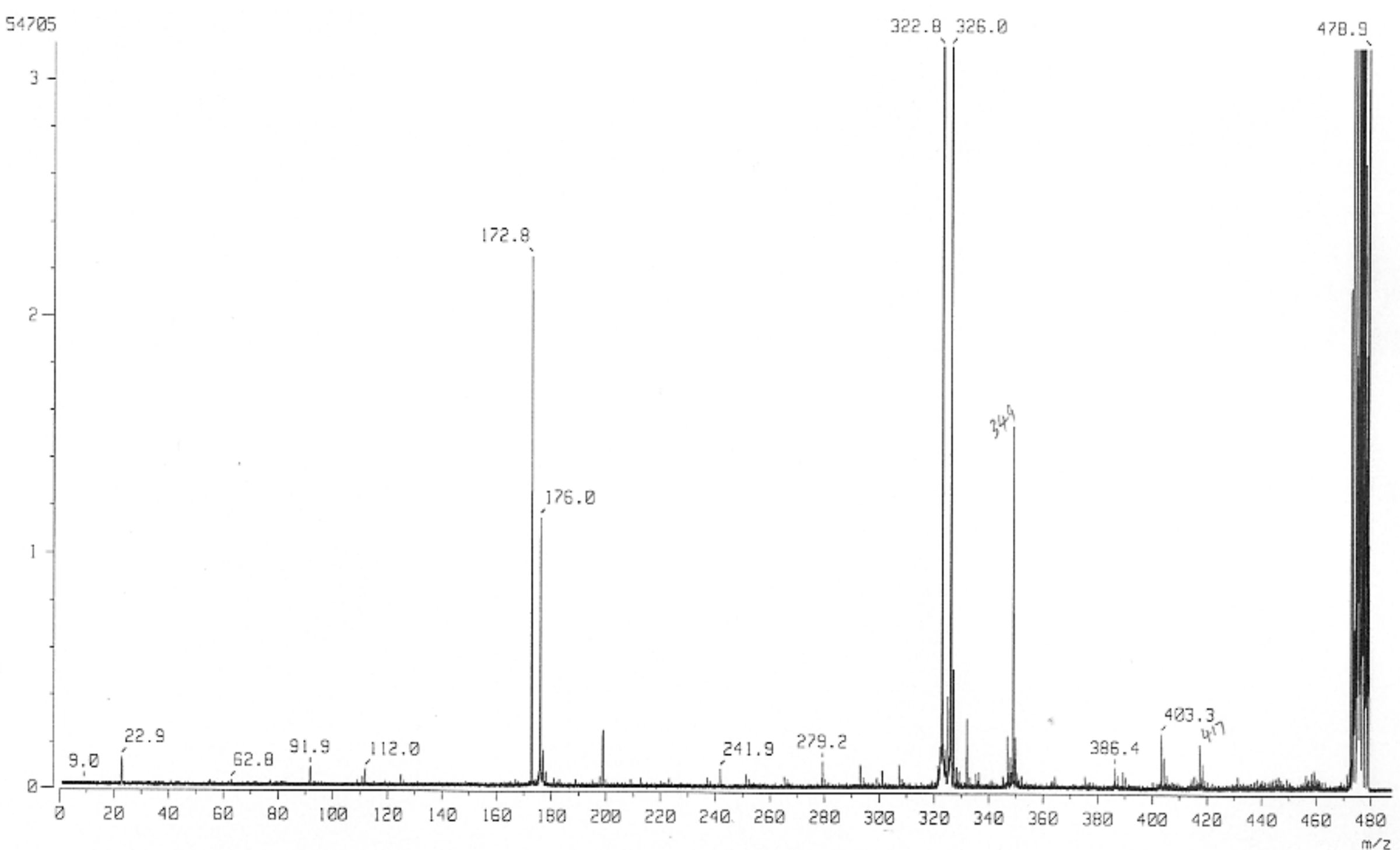

Figure S8: FAB-CID tandem mass spectrum of FAME of compound 6. 


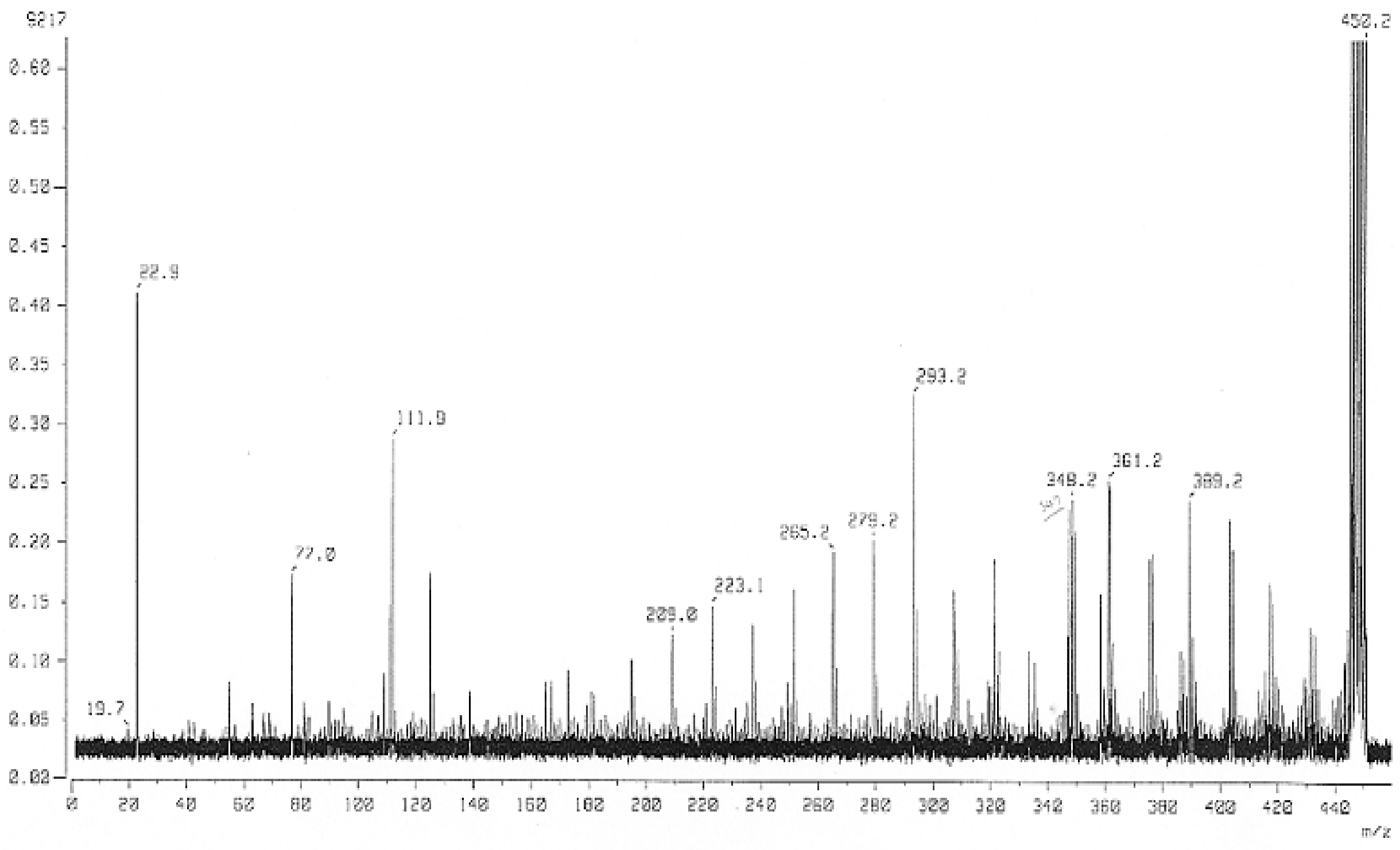

Figure S9: FAB-CID tandem mass spectrum of FAME of compound 2. 


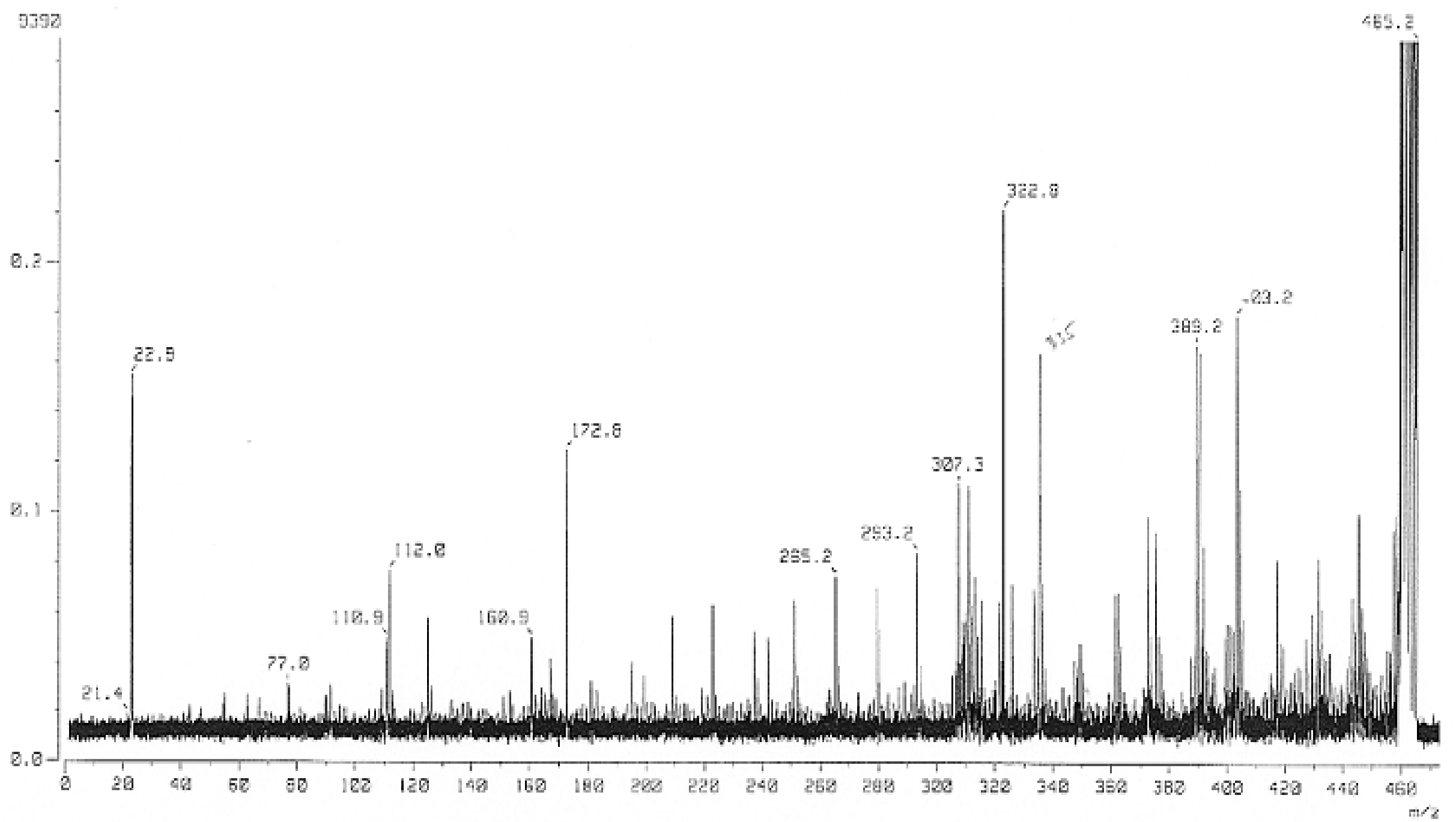

Figure S10: FAB-CID tandem mass spectrum of FAME of compound 8. 


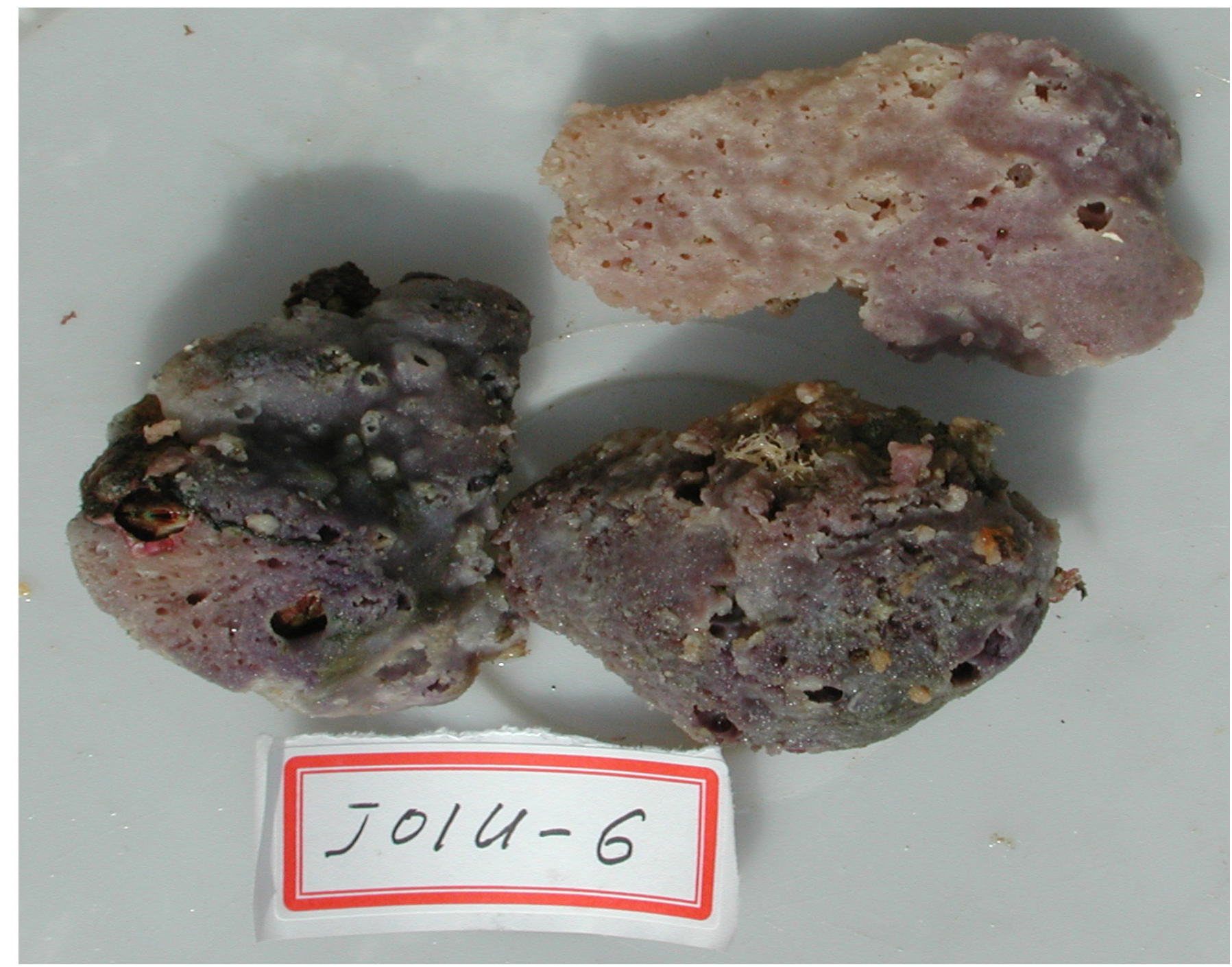

Figure S11: Color photograph of the sponge Haliclona (Reniera) sp. 